\title{
Strategic construal of in and out in English particle verbs (PVs)
}

\author{
Renata Geld and Ricardo Maldonado \\ geldrenata@gmail.com / msoto@servidor.unam.mx \\ University of Zagreb, Croatia / Universidad Nacional Autónoma de México, Mexico
}

\begin{abstract}
$^{1}$
The central aim of this work is to describe the strategic construal of in and out in English particle verbs. The term strategic construal assumes the following: 1) exploration of strategic thinking in L2 learning and processing, and 2) exploration of dynamic and subjective construction of meaning pertaining to the human ability to understand and portray the same situation in alternate ways (Langacker 1987). In other words, the paper relies on two theoretical paradigms with self-evident commonalities - a strong link between language and cognition, and the insistence on the individual and subjective nature of meaning construction. The aim was to investigate whether L2 users of English are aware of the symbolic nature of language when dealing with highly schematic linguistic categories. Our hypotheses were that construal of in and out is comparable to their cognitive linguistic description in English as L1 and that it shows a cognitively motivated path from the topological to the aspectual. Both hypotheses have been confirmed.
\end{abstract}

Key words: strategic construal, particle verbs, in, out

\section{INTRODUCTION}

The acquisition of particle verbs (PVs) constitutes one of the greatest difficulties when it comes to learning English as a second language. PVs vary considerably in the degree of opacity/transparency ${ }^{\underline{2}}$ they exhibit, which raises the question as to the possible strategies the second-language user needs to develop in order to learn them. Two obvious examples of this are put out in (1) and take in in (2):

\section{Put out}

1. a. 'turn off the light'

b. 'to injure your back, shoulder or hip'

c. 'make somebody go to sleep or unconscious

d. 'broadcast, publish or issue'

e. 'make a figure, result, etc. wrong'

f. 'make trouble, problems or extra work' 
Take in

2. a. 'introduce something in a pocket'

b. ' 'make a piece of clothing narrower or tighter'

c. 'make somebody believe something that is not true'

d. 'understand or absorb something'

Given such array of meanings one may simply assume that the second-language user has no other choice than learn the idiom by rote. A less passive interpretation may wonder about possible strategies the L2 user could employ and whether they resemble the processes claimed to be activated in the first language learning and meaning construction, that is those used by native speakers. One obvious strategy is to use full compositionality by adding the meaning of the verb to that of the particle as expected in examples like (1a) and (2a). Yet, other possibilities are also at hand, particularly when abstract and metaphorical readings are at play, as in cases (b) to (f). Given the fact that not everything is transparent, learners may attend mainly to the meaning of the verb and pay little attention to in or out. Alternatively, they may also focus on the value of the particle as a schematic representation determining the behaviour of the verb. In this paper we focus on the way the particle is interpreted by L2 users of English. The particle may be interpreted in more or less schematic terms. Of course, metaphorical and metonymic connections could allow further interpretations such that out and in could be seen as representing enclosed or non-enclosed locations, abstract areas, different abstract situations and events, and even aspectual meanings related to the terminal or the initial part of an event.

As we show in the next section, a considerable amount of research has been conducted on the construal of PVs, particles, and prepositions in L1. What has not been identified with enough precision are the specific strategies employed by L2 users in the process of constructing meaning of English PVs, and even more specifically, whether these strategies resemble processes assumed to be activated by native speakers of English. Another issue of strategic meaning construal that has not been properly addressed is whether the strategies employed by L2 users are applied randomly to tackle individual problems or they follow general cognitive principles to construct language. In this study we attempt to identify the strategies employed to make sense of the meaning of PVs with in and out through experimental data from Croatian and Mexican users of English. 
Having two groups of speakers of unrelated languages will enable us to identify both the language-specific strategic features developing from each language as well as the strategic coincidences suggesting the presence of general cognitive patterns operating in the acquisition of English PVs.

\section{THEORETICAL BACKGROUND}

According to cognitive grammar (Langacker 1987, 1991, 2000a), “complex expressions exhibit only partial compositionality” (Langacker 2000a: 16, original emphasis). The meaning of a complex expression constitutes either an elaboration or an extension in relation to what is expected as compositional value. When a novel expression is used for the first time, its meaning is constructed in a given context. The conventionally determined import of the expression at best approximates its actual contextual understanding. Over time, and through frequency of usage, it achieves the status of a lexical item. In the process of fixation, recurrent aspects of its meaning, including some of a non-compositional origin "become entrenched and establish themselves as a part of what eventually emerges as its conventional linguistic value” (Langacker ibid.: 15). Thus, complex expressions are partially compositional because, on the one hand, the relationship between a composite structure and its components is not arbitrary and, on the other hand, a composite structure is not constructed out of its components, nor it is fully predictable. Langacker concludes (ibid.: 16, original emphasis):

\footnotetext{
Rather than constituting a composite structure, the component structures correspond to certain facets of it, offering some degree of motivation for expressing the composite conception in the manner chosen. And because the composite structure represents a distinct entity that is not in general reducible to its components, a construction is described as an assembly of symbolic structures.
}

For the analyses offered in this work, the most important dimension of lexical semantics is analysability, that is, "the extent to which speakers are cognizant of the presence and the semantic contribution of component symbolic elements" (Langacker ibid.: 127). A novel expression is easily analysable because a speaker manipulates the components in the process of constructing it. If we transfer this phenomenon from the first language domain, i.e. the native speaker's perspective, into the domain of second language, we shall notice considerable parallelism: when they come across a new construction, second-language users may attempt to analyse it in terms of its components, especially 
when individual components are already well entrenched in their L2, as is frequently the case with PVs. However, L2 users soon realize that the expected compositional meaning is far from a simple sum of meanings. They appreciate that components are not predetermined or fixed, and that complex structures are not put together in a strictly compositional manner. Over time, most learners abandon the idea of the building-block metaphor ${ }^{3}$, which implies that smaller constituents are building blocks out of which larger constituents are constructed, and their expectations change. What follows runs roughly in two directions: a) L2 users either start believing that whatever happens in the process of constructing and making sense of meaning is too elusive to be captured and understood, so they stop thinking about meaning and attempt to store whatever they encounter "intact" and in larger chunks, or b) despite having rejected the idea of the building-block metaphor, they tacitly nurture the idea of linguistic motivation, and they attend to various aspects of meaning and form. Naturally, their attention depends on various language-internal and language-external factors, and their strategic meaning construal is deeply immersed in prior linguistic and world experience (see Figure 1).

The theoretical framework assumed in this paper, and shown schematically in Figure 1, suggests the following: first, language is an experiential phenomenon and it is intimately related to other cognitive processes, such as attention, comparison, perspective and gestalt. In broader terms, the emergence of complex language representations results from "simple learning mechanisms operating in and across human systems of perception, motor action and cognition while exposed to language data in communicatively rich human social environments” (Ellis 2003) ${ }^{4}$. Furthermore, meaning construal is dynamic and subjective, and construal operations (e.g. metonymy, metaphor, fictive motion, categorization, deixis, etc.) are viewed as instances of the abovementioned general cognitive processes as aspects of a conceptual structure. Finally, strategic meaning construal and L2 learning inevitably depend on whatever precedes. Being entangled with L1 and experiential knowledge of the world, L2 both relies on and mirrors various cognitive processes that constitute conceptual structure in L1. However, this specific cognitive state of L2 users, burdened with prior linguistic knowledge and experience (MacWhinney 2001, 2006), also functions as a constraint in the process of language acquisition and strategic meaning construal ${ }^{\underline{5}}$. 


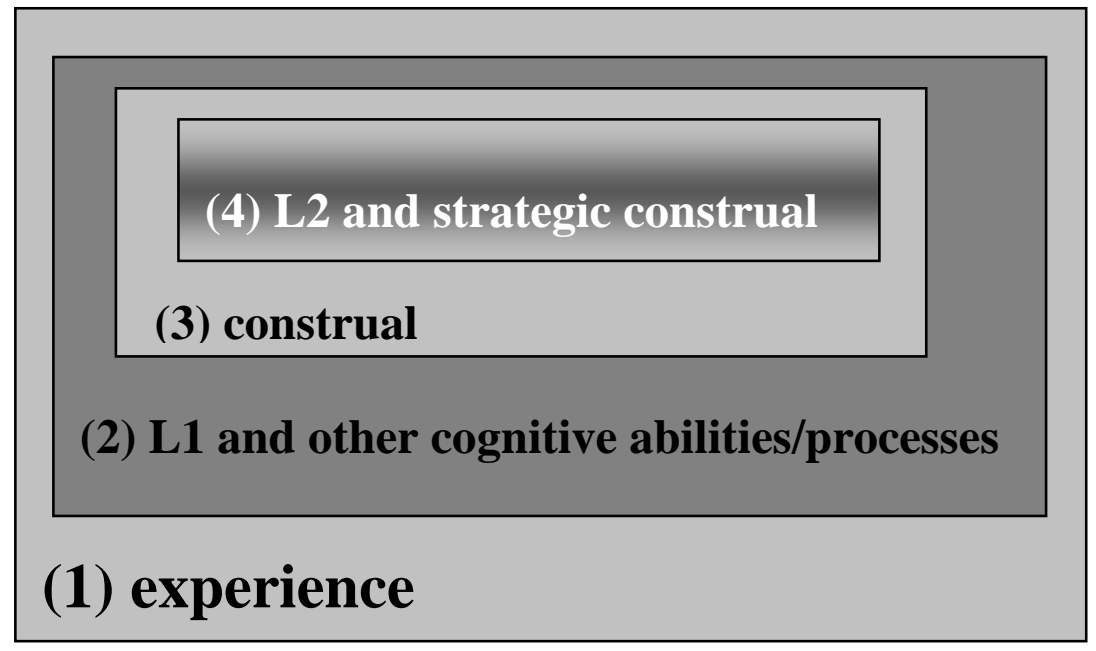

Figure 1. Integrated model of second-language acquisition (Geld 2006: 108).

For example, Mexican users of English, coming from a linguistic environment that maps the core schema exclusively onto the verb, are likely to encounter considerable problems while processing English particle verbs where the core schema ${ }^{6}$ is mapped onto the particle (see Geld this volume). However, if their attention shifts to form, it might activate aspects of conceptual structure, such as underlying image schemas or metaphorical mappings in cases of non-literal meanings, which, in turn, might facilitate input being processed and transformed into intake. Thus, specific language realizations inherited from L1 might constrain and filter L2 input, but, on the other hand, the activation of underlying cognitive processes, which have been proved to be common cross-linguistically, is likely to facilitate the recognition of how form encodes meaning.

Returning to the issue of how L2 users perceive language, we wish to suggest that all of them, irrespective of their inclination to view language either as an arbitrary or as a cognitively motivated system, process language and construct meaning by attending to both meaning and form. In other words, their attention is constant but it varies quantitatively and qualitatively. This line of thought is in accordance with theoretical linguistic constructs such as Langacker's analysability (1987, 2000a), as well as with L2 research results on implicit vs. explicit knowledge, and their relation to consciousness (see for example Doughty 2001, Hulstijn 1989, and Schmidt 1990, 1993a, 1993b, 1994a, 1994b, 1998, 2001). Describing native speaker's understanding of semantic structure and the concept of analysability, Langacker discusses terms like "aware”, “cognizant” and "recognize”, and asks whether the claim that a speaker is "aware” or 
"cognizant" of the components within a composite structure implies that "these components are consciously recognized and attended to", and he proceeds by suggesting the following (1987: 459-460):

There is nothing in the definition of analysability (characterized at the level of cognitive events) that inherently restricts it to the domain of consciousness. Recognition is accomplished through acts of comparison, which are assumed to be ubiquitous to all domains and levels of cognitive processing.

If we relate this to the issue of the relationship between explicit and implicit knowledge in the process of learning a second language, we cannot but agree with Schmidt (1990), who suggests that the explicit/implicit contrast represents a continuum and that there is no learning without 'noticing'. However, we wish to challenge his doubt that learning that occurs without learners' being aware of learning plays a minor role in the field of second language (Schmidt 1998, 2001). Having embraced the insights from cognitive psychology, and hence assuming that various cognitive processes such as attention or comparison are present in all domains and levels of cognitive processing and construction of meaning, we may conclude that the abovementioned continuum is by itself sufficient to describe the nature of knowledge. In other words, in the process of learning, learners both consciously and subconsciously attend to various aspects of language and pass judgments that result in constant restructuring of their knowledge. Thus, if we wish to investigate the process of strategic construal, i.e. meaning construal in L2, it is legitimate to do so by shifting our learners' attention to form and asking specific questions about meaning. We will ask questions about the meaning of a PV attending to the meaning of its components and the way they interact to form the PV's complex meaning. The learner's conscious reasoning about composite wholes, such as particle verbs, might tell us a great deal about how components motivate and highlight selected facets of the composite meaning. Naturally, analysability of composite wholes very much depends on the life they live as conventional units. They have an elaborate semantic value which lies in their extra-compositional specifications that correspond to facets of contextual meaning and, in addition to that, they diverge from their specifications by extension or elaboration (Langacker 1987).

In the case of particle verbs, dramatically extended meanings often prevent the activation of component meanings along with the meaning of the whole. However, we wish to suggest that comprehension failures that are likely to occur while processing 
input containing these constructions tend to trigger focus on form, which is characterized by specific (re)-allocations of attention that are determined by the semantic "weight" of their components ${ }^{7}$. Thus, as shown by Geld (this volume), we might expect focus on particles when they collocate with semantically light lexical parts $^{\underline{8}}$ and, conversely, more focus on lexical parts when they are heavy verbs that are bound to make a more substantial semantic contribution. The aim of this paper is to offer a more detailed description of the contribution of particles, and to investigate the semantic nature of in and out in L2 in terms of its resemblance to the nature of these particles in English as L1.

\section{II.1. How in and out structure space}

Space and spatial relations have been of central importance for linguists for decades (see for example Bennett 1975, Bowerman 1996a, 1996b, Bowerman and Choi 2003, Brugman 1981, Casad and Langacker 1985, Choi and Bowerman 1991, Fillmore 1968, Herskovits 1982, Jackendoff 1983, Johnson 1987, Lakoff 1987, Langacker 1982, 1987, Lindner 1981, Talmy 1982, 1983, 2000a, 2000b, Tenbrink 2007, Vandeloise 1984, 1991, 1994, Zubin and Svorou 1984). Likewise, the properties of in and out in coding fundamental spatial relations have attracted a number of authors, such as Herskovits (1982, 1988), who gives detailed and much-quoted accounts of in; Lindner (1981), whose account of out is an exhaustive analysis of its roles in PV constructions; RudzkaOstyn (2003), with her insightful applied work on the role of particles in PV constructions; Dewell (2005), who contributes with a fresh account of the old issue of the dynamicity of CONTAINMENT (Johnson 1987, Lakoff 1987); and Evans and Tyler (2004), who, on the other hand, argue against the assumption that there are "dynamic" prepositions that denote motion. Instead, they propose that there are clear principles when a particular sense is conventionalized, i.e. instantiated in memory, and when it is a contextualized usage.

There are several distinct meanings of in and out that are directly relevant to our central discussion. First, the meanings of out described by Lindner (1982: 81-140): a) out that codes "the removal or departure of one concrete object from within another object or space”; b) out whose meaning codes foregrounding a single (static) configuration; c) 
meaning extensions pertaining to abstract displacement (landmarks are: some abstract, coherent complex of information; abstract neighbourhood of possession; privacy; change from hiddenness to accessibility; change from accessibility to inaccessibility, including non-function/non-existence; d) extensions and expansions in time and space, including full temporal extension of an event; and e) the meaning of "moving away", including the spatial dimension and the sense of initiation, i.e. the start of a particular activity.

Second, the following meanings of in: a) the prototypical meaning of containment with both its static topology and dynamic characterization (Dewell 2005, Herskovits 1982, 1988, Johnson 1987, Lakoff 1987), and b) the vantage point as an interior/exterior cluster (Evans and Tyler 2004).

\section{RESEARCH}

\section{III.1. The hypotheses, instrument, sample and procedure}

As already suggested, the aim of the research was to establish what cognitive (learning) strategies (see Geld 2006, Geld and Letica Krevelj 2011, O’Malley and Chamot 1990), as aspects of meaning construal, reveal about the nature and role of particles in PV constructions.

Our hypotheses were the following:

1) L2 users are aware of the symbolic nature of language even while dealing with highly schematic linguistic categories;

2) strategic construal of in and out is comparable to their cognitive linguistic description in English as L1;

3) strategic construal of in and out shows a cognitively motivated path from the topological to the aspectual;

Our overall aim was twofold: first, to investigate semantic determination in terms of the lexical (verb dominant), topological (schematic particle dominant), and compositional (verb particle sum) nature of construal of the composite wholes ${ }^{\underline{9}}$ in question (see Geld, 
this volume), and second, to investigate the construal of particles in greater detail, as evident from the hypotheses stated above.

The sample consisted of 100 users of English - 68 English majors from Croatia and 32 from Mexico. The instrument used was a questionnaire that contained 20 particle verbs combining light (go, take and put) and heavy (call, cut, break, draw, pull, shut and write) lexical parts with in and out. The 46 meanings selected for the research material were those qualified as obscure (metaphorical) by a triangulation study ${ }^{\underline{10}}$ conducted prior to the main stage of the research.

The first step in the main stage $\mathrm{e}^{11}$ of the research was to test our research participants' language proficiency. After the proficiency test, the participants were scheduled to attend two separate sessions to complete the research questionnaire. In order to conduct both quantitative and qualitative analyses, all the answers were first copied, grouped and sequenced alphabetically.

A methodological assumption should be put forward. Given the fact that there is considerable literature on the construal of in and out in native speakers, we will contrast our results with well establish findings on the topic. Thus there will not be a control group.

\section{III.2. The data and results}

We obtained 4198 answers (2207 for out and 1991 for in). Since we were interested in the construal of particles, we focused on the following two categories: 1) topological determination, and 2) compositional meaning $\underline{\underline{12}}$.

The answers were further categorized according to the construal of the particles. Ten categories were established for out and 9 categories for in. The categories correspond to schematic representations of our participants’ construals.

\section{III.2.1 Classification of verb groups}

In order to discuss specific construals of particles, we first grouped the meanings of the PVs used in the research questionnaire ${ }^{\underline{13}}$ : 
1) Processual topology (concrete) involves motion, entering or leaving some space (G2): put out ('to injure your back, shoulder or hip'); go in ('become hidden'); take in ('make a piece of clothing narrower or tighter'); call out ('ask somebody to come and help you when there is an emergency'); cut out ('prevent something from reaching somewhere'); break out ('become covered in something); break out ('escape'); shut out ('stop something from entering'); call in ('send for somebody professional and official'); call in ('make a short visit, usually on the way to another place'); break in ('to wear something until it is comfortable'); draw in ('become dark as the sun hides earlier when winter approaches'); pull in ('move to the side of the road to stop'); shut in ('trap or injure something by closing something tightly around it'); write in ('write and send a message to ask or complain').

2) Processual topology (abstract) (G4) involves a participant who becomes or stops being a part of some state or abstract dominion: take out ('kill somebody'); take out ('obtain an official document or a service'); put out ('make somebody go to sleep or unconscious'); put out ('broadcast, publish or issue'); put out ('make a figure, result, etc. wrong); put out ('make trouble, problems or extra work'); go in ('be understood'); take in ('make somebody believe something that is not true'); take in ('understand or absorb something'); put in ('officially make a claim'); put in ('to spend time or effort doing something'); put in ('interrupt'); put in ('elect political party as the government'); draw out ('make somebody feel less nervous or shy'); draw out ('make something last longer'); pull out ('stop being involved in something'); shut out ('refuse to allow a person to share your thoughts or feelings'); call in ('make a public request for a product to be returned'); cut in ('interrupt somebody's conversation'); break in ('interrupt a conversation'); break in ('get somebody accustomed to something new'); pull in ('attract people in large numbers').

3) Aspect (termination) (G5): go out ('stop burning'); go out ('stop being fashionable'); put out ('switch something off'); put out ('extinguish, stop from burning'); cut out ('stop working'); cut out ('stop doing something'); write out ('write something and include all the necessary information'). 
4) Aspect (inception) (G6): break out ('begin suddenly’).

In the first part of the research each answer was first labelled with a general code referring to the type of determination ${ }^{\underline{14}}$ (or another general code if determination could not be defined). In the cases of topological determination and compositionality, the answer was also given a numerical code denoting the meaning of the topological part of the construction.

\section{III.2.2. Results for out}

In this section we list the types of strategic construal of out for each group of meanings outlined in the previous section. Having the meanings organized in the abovementioned four groups, what we needed to find out were the type of strategies our participants stated that they used to figure out the meaning of the PV. In what follows "PC+Number" stands for the coding of the particle. The percentage in brackets shows the number of answers containing explanations of the particle stated after the colon.

1) For the first group of meanings ( $G 2$ = processual topology - concrete) the meaning of out was construed as follows:

a) PC1 (11.50\%) - processual topology (concrete/physical). Out is: going out or leaving an enclosed space; going out of anything that surrounds you or confines you; going out or leaving a container (human bodies, houses, buildings, drawers, etc) - very literal, physical, and concrete images.

The meaning could be shown schematically in the following way:

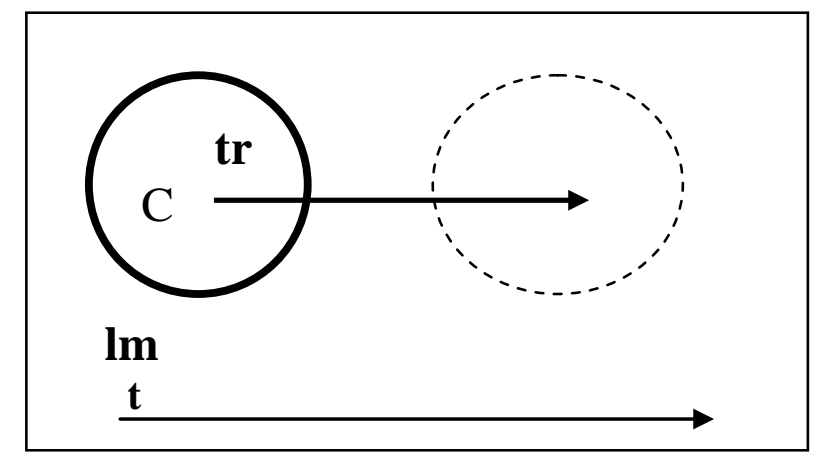

Figure 2. Strategic construal of out - processual topology (1). 
b) PC3 (12.10\%) - static topology (concrete/physical) - out of our dominion or out of the 'usual' place. Out is: out of where we are; out of our world; out of our reach; out of the normal position; out of its place; displaced; out of its physical boundaries; out of its physical limits (see Figure 3).

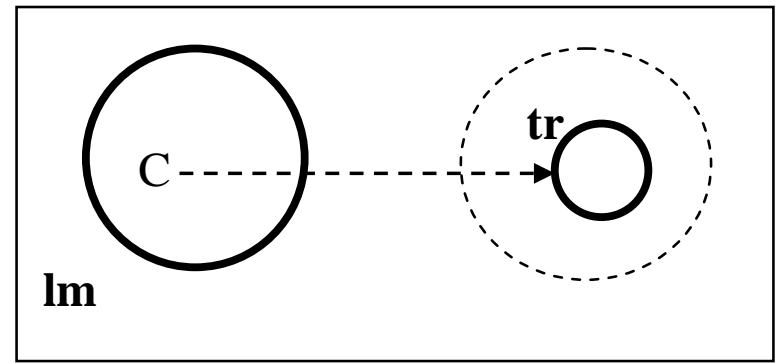

Figure 3. Strategic construal of out - static topology (1).

c) PC2 (3.25\%) - abstract topology (static displacement/change of state). Out is: out of the previous state; out of the previous activity; out of the original state; out of the normal state; out of routine; out of the usual; out of order; out of the circuit; out of what is expected or correct. The change of state implied in the construal described above could be graphically approximated in the following way:

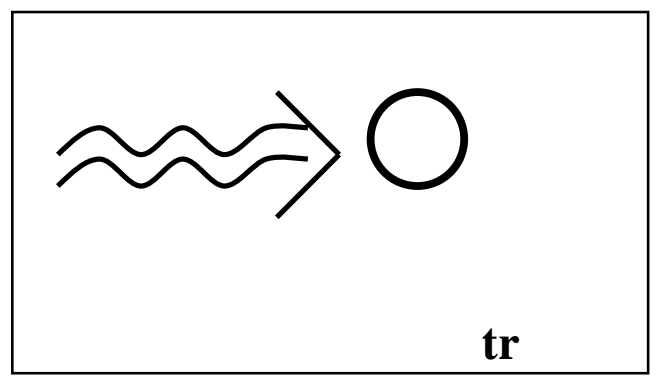

Figure 4. Strategic construal of out - change of state.

d) PC4 (0.2\%) - out is: absence; absent; isolation; not present; not here; not seen; not visible (see Figure 5).

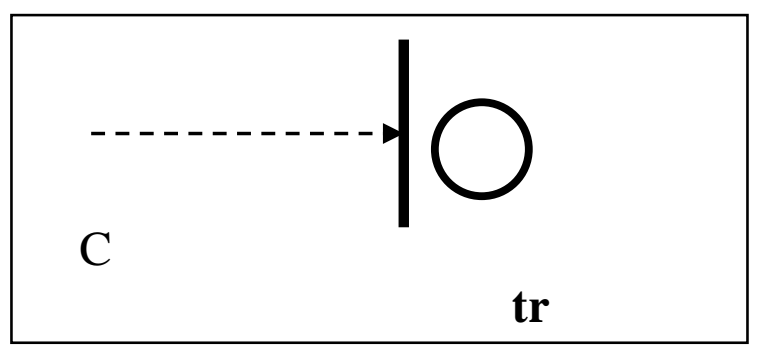

Figure 5. Strategic construal of out - invisibility \& inaccessibility. 
e) PC5 $(1.0 \%)$ - processual topology without direct reference to the container. Out is: disappear; disappearing; leaving (see Figure 6).

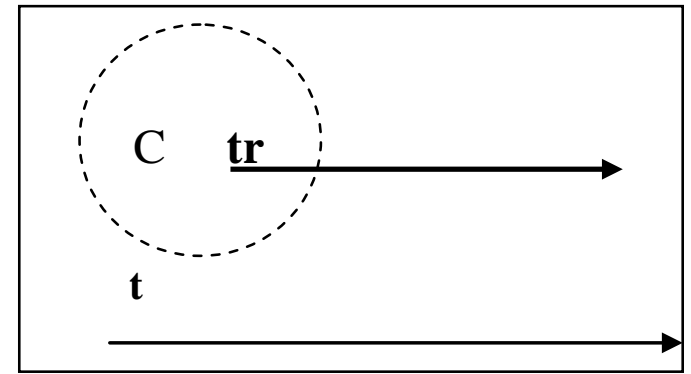

Figure 6. Strategic construal of out - processual topology (2).

f) PC7 (1.20\%) - aspectual (termination) - out is: something finished; something ended; end; completely; completely stopping; termination; all of something (see Figure 7).

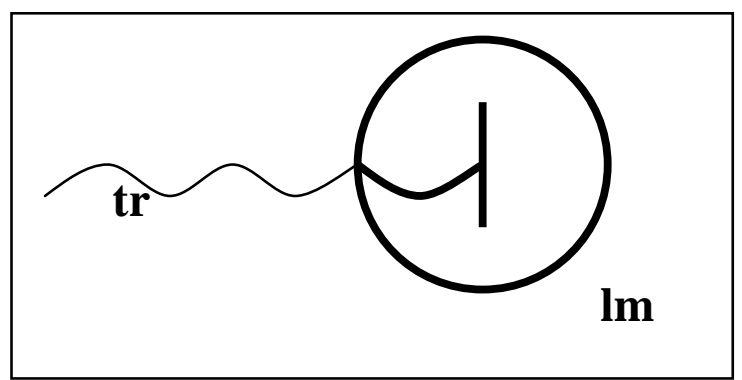

Figure 7. Strategic construal of out - aspect (termination).

g) PC9 (7.55\%) - static topology (both concrete and abstract) - focus on the space outside our immediate dominion. Out is: outside, “out” where other people are; visible; not hidden; out in the open; out in the larger area; out in all directions or surrounding space. The construal is shown in Figure 8.

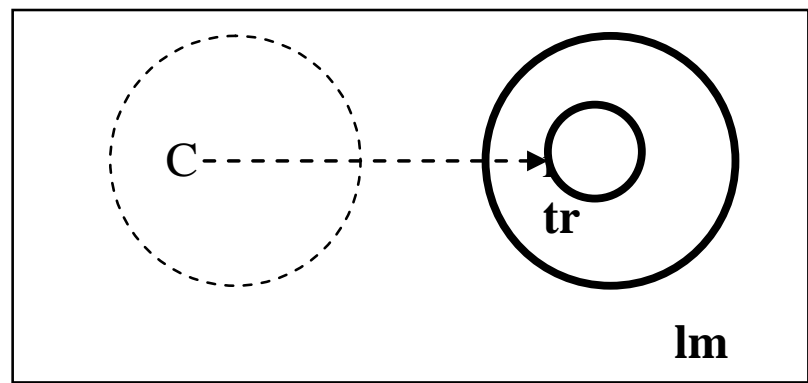

Figure 8. Strategic construal of out - static topology (2). 
h) PC12 (0.6\%) - established metaphor. Out is: out of the group; not belonging; free; freedom; something discarded; something unacceptable; something negative (see Figure 9).

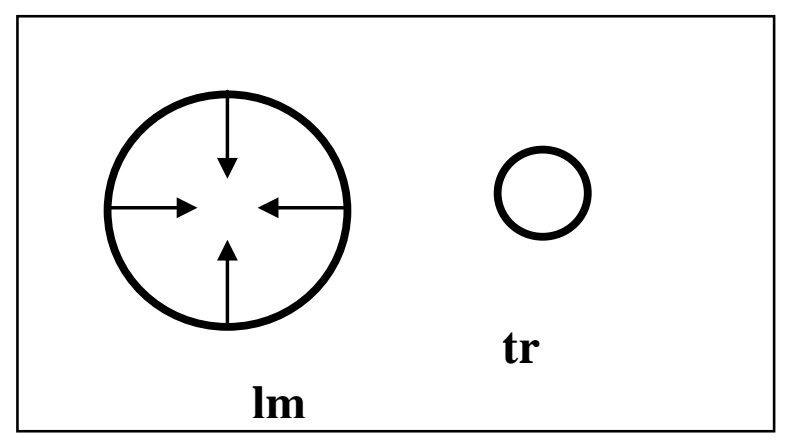

Figure 9. Strategic construal of out - 'out of the group'.

i) PC14 - (2.7\%): there is some kind of reverse viewing; change of focus. The meaning of out in, for example, take out meaning 'kill' is interpreted in two ways: a) 'a person is taken out of life', or b) 'life is taken out of a person's body; or, for example, in draw out meaning 'make less nervous or shy', out is: a) 'out of the state of nervousness, or b) 'nervousness taken out of the body'.

2) The second group of meanings is G4 (processual topology - abstract). The meaning of out was construed as follows:

a) PC1 (6.51\%) - processual topology (concrete/physical) (see Figure 2).

b) PC3 (5.61\%) - static topology (concrete/physical) (see Figure 3).

c) PC2 (17.64\%) - abstract topology (static displacement) (see Figure 4).

d) PC4 (0.87\%) - out is: absence; absent; not present; not here; isolation; not seen; not visible (see Figure 5).

e) PC5 (0.55\%) - processual without direct reference to the container (see Figure 6).

f) PC7 (0.73\%) - aspectual (termination) (see Figure 7).

g) PC9 (8.28\%) - static topology (both concrete and abstract) focus on the space outside our immediate dominion (see Figure 8).

h) PC12 (1.13\%) - established metaphor. Out is: out of the group; not belonging; free; freedom; something discarded; something unacceptable; something negative (see Figure 9). 
i) PC14 (5.41\%) - reverse viewing (change of focus).

3) For the third group of PV meanings (G5: aspectual - termination), the construals are the following:

a) PC1 (3.97\%) - processual topology (concrete/physical) (see Figure 2).

b) PC3 (6.51\%) - static topology (concrete/physical) (see Figure 3).

c) PC2 (8.10\%) - abstract topology (static displacement) (see Figure 4).

d) PC4 (3.94\%) - out is: absence; absent; not present; not here; isolation; not seen; not visible (see Figure 5).

e) PC5 (2.06\%) - processual without direct reference to the container (see Figure 6).

f) PC7 (11.61\%) - aspectual (termination) (see Figure 7).

g) PC8 (0.43\%) - out emphasizes the action.

h) PC9 (1.14\%) - static topology (both concrete and abstract) (see Figure 8).

i) PC12 (1.0\%) - established metaphor. Out is: out of the group; not belonging; free; freedom; something discarded; something unacceptable; something negative (see Figure 9).

j) PC14 (2.43\%) - there is some kind of reverse viewing (change of focus).

4) For the fourth group of PV constructions (G6: aspectual - inception), the following construals of out were established:

a) PC1 (7.61\%) - processual topology (concrete/physical) (see Figure 2).

b) PC2 (3.26\%) - abstract topology (static displacement) (see Figure 3).

c) PC9 (11.96\%) - static topology (both concrete and abstract) (see Figure 8).

d) PC13 (7.61\%) - aspectual (inception). Out is: the action starts; the activity is in effect; things are in effect; things are in existence; things begin, see Figure 10 below. 


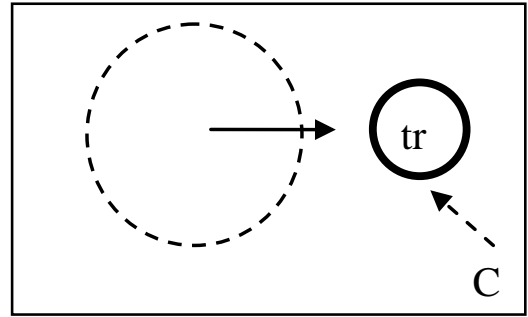

Figure 10. Strategic construal of out - aspect (inception).

Table 1. Strategic construal of out - summary.

\begin{tabular}{|c|c|c|c|c|}
\hline & $\begin{array}{c}\text { G2 } \\
\text { processual } \\
\text { topology } \\
\text { concrete }\end{array}$ & $\begin{array}{c}\text { G4 processual } \\
\text { topology } \\
\text { abstract }\end{array}$ & $\begin{array}{c}\text { G5 } \\
\text { aspectual } \\
\text { termination }\end{array}$ & $\begin{array}{c}\text { G6 } \\
\text { aspectual } \\
\text { inception }\end{array}$ \\
\hline $\begin{array}{c}\text { PC1 - processual } \\
\text { topology } \\
\text { (concrete/physical) }\end{array}$ & $11.50 \%$ & $6.51 \%$ & $3.97 \%$ & $7.61 \%$ \\
\hline $\begin{array}{c}\text { PC2 - abstract } \\
\text { topology (static } \\
\text { displacement/change of } \\
\text { state) }\end{array}$ & $3: 25 \%$ & $17.64 \%$ & $8.10 \%$ & $3.26 \%$ \\
\hline $\begin{array}{c}\text { PC3 - static topology } \\
\text { (concrete/physical) }\end{array}$ & $12.10 \%$ & $5.61 \%$ & $6.51 \%$ & $0.00 \%$ \\
\hline PC4- absence & $0.20 \%$ & $0.87 \%$ & $3.94 \%$ & $0.00 \%$ \\
\hline $\begin{array}{c}\text { PC5 - processual } \\
\text { topology (without } \\
\text { direct reference to the } \\
\text { container) }\end{array}$ & $1.00 \%$ & $0.55 \%$ & $2.06 \%$ & $0.00 \%$ \\
\hline $\begin{array}{c}\text { PC7 - aspectual } \\
\text { (termination) }\end{array}$ & $1.20 \%$ & $0.73 \%$ & $11.61 \%$ & $0.00 \%$ \\
\hline $\begin{array}{c}\text { PC8 - emphasis on the } \\
\text { action }\end{array}$ & $0.00 \%$ & $0.00 \%$ & $0.43 \%$ & $0.00 \%$ \\
\hline $\begin{array}{c}\text { PC9 - static topology } \\
\text { (both concrete and } \\
\text { abstract) }\end{array}$ & $7.55 \%$ & $8.28 \%$ & $1.14 \%$ & $11.96 \%$ \\
\hline $\begin{array}{c}\text { PC12 - established } \\
\text { metaphor }\end{array}$ & $0.60 \%$ & $1.13 \%$ & $1.00 \%$ & $0.00 \%$ \\
\hline $\begin{array}{c}\text { PC13 - aspectual } \\
\text { inception }\end{array}$ & $0.00 \%$ & $0.00 \%$ & $0.00 \%$ & $7.61 \%$ \\
\hline PC14 - reverse viewing & $2.70 \%$ & $5.41 \%$ & $2.43 \%$ & $0.00 \%$ \\
\hline $\begin{array}{c}\text { PCon } \% \\
\text { (1) }\end{array}$ & & & & \\
\hline
\end{tabular}

\section{III.2.3. Discussion for out}

For the group of PV meanings labelled G2, 11.50\% of the answers implied concrete processual topology (PC1), which means that their strategic construal of the particle corresponds to our (i.e. researchers'/linguists') construal of the whole PV construction. 
This strategic construal overlaps with the prototypical meaning of out, as described by Lindner (1982). It should be repeated here that our selection of PVs was based on the triangulation study conducted with the aim of discriminating literal from metaphorical meanings. All the PVs used in the research were those whose rating had shown tendencies towards the metaphorical interpretation. However, even within that sample of PVs certain meanings were conducive to particles being construed as implying concrete, physical processes and topology. This is more than evident in the group of meanings discussed in this section.

The second type of strategic construal, PC3 (static topology), which is almost as frequent as the previous one (12.10\%), points to a more static construal of the particle. If we consider the fact that we are dealing with the construal of particles in the cases of both topological determination and compositional meanings, this particular construal of the particle might be interpreted in two ways. First, if this static topology refers to the previously established topological determination, it suggests that, in the process of constructing meaning, a certain number of L2 users of English more readily attend to the resultant stage of the event described ('out of our world', 'out of our reach', 'out of the normal position', etc.). Second, if the static topology refers to the construal of the particle in the cases of established compositionality, it suggests that the verb denotes the process and the particle denotes the final stage. In either case the final state is what is most relevant.

The same dual interpretation can be given for the construal involving abstract topology (PC2). Even though only $3.25 \% \frac{15}{}$ of the participants construed this rather concrete group of meanings in a more abstract way, it still might be taken as a piece of evidence signalling that L2 users have different starting points within a lexical category ${ }^{\underline{16}}$. Where and how they start is likely to depend on various aspects of their experience and knowledge. For example, the meaning of out in the verb put out meaning 'to injure your back, shoulder or hip' is more likely to be construed as concrete and topological by someone who knows exactly what happens when such an injury occurs - a particular bone gets 'out of its place'. However, it can be easily identified with a more abstract meaning such as 'out of the original or normal state'. This also relates to what was suggested by Lindner, who stresses that we should not attempt to categorize particular meanings as an exclusive member of only one category ${ }^{\frac{17}{}}$. Speakers (of L1) extract 
regularities from particular constructions and construct meanings accordingly, but they are free to extract multiple patterns from a given set of forms. We believe that the same process may be claimed for L2 speakers/learners. This is particularly the case since the concrete and the abstract interpretation have enough commonalities to construe the event in alternate ways.

The third most frequent construal, PC9 (concrete and abstract static topology - 7.55\%), also implies static topology. However, this construal involves an important new element - focus on the space outside our immediate dominion. Furthermore, it includes the concept of visibility and accessibility described in Lindner in English as L1. These meanings are often related to the non-transparency of LMs. They hide their contents and make them invisible, but they are often only vaguely specified and they refer to various states denoting obscurity. Thus, out often denotes 'change of state from non-visible to visible'. This resultant change approximates the strategic construal of out labelled PC9.

The second group of meanings (G4) had been classified as denoting abstract processual topology. The most frequent construal of the particle in this group was PC2 (17.64\%) abstract topology (static displacement). This static aspect of the construal is actually the central element found for this group of meanings. This is confirmed by the frequencies established for PC3 (5.61\%) and PC9 (8.28\%), which both imply static topology, and the only difference between them is the viewing arrangement. More specifically, the construal labelled PC3 is deictic and partly egocentric. The location of the speaker operates as a reference point to calculate the location of others. This is evidenced by answers describing out as 'out of our world', 'out of our reach' or 'out of where we are', as opposed to answers belonging to PC9, which describe out as 'outside where other people are', 'out in the open', 'out in the larger area', and so forth, which do not have a deictic organization. In terms of what has been said about the nature of out in English as L1, these two meanings are consistent with what Lindner explained by using the model of an evolutionary cycle. There are two basic viewer-defined regions (the potential private and the actual public) that serve as LMs for out. Both Mexican and Croatian users of English have recognized these two regions as an important aspect in the process of meaning construction of this particle. However, $6.51 \%$ of the answers referred to concrete processual topology, which suggests that degrees of concreteness and literalness are indeed very subjective. In this particular case, our participants' strategic 
construal showed a tendency towards the concrete whereas ours leaned towards the more abstract. This may be a consequence of the pervasiveness of the concrete construal to operate as the base for the construction of abstract meanings. Thus L2 users may take advantage of the concrete representation in order to interpret abstract configurations. In contrast, the linguist's view may be used to assume such a concrete basis and allow for the abstract representations to be profiled. In other words, common speakers tend to be more conservative than linguists, particularly cognitive linguists, who see metaphorical extensions as the natural shape of human language.

Finally, 5.41\% of the answers implied a kind of reverse viewing pertaining to our bodies being perceived as containers. Thus, for example, the meaning of take out 'kill' is explained by saying that 'life is taken out of a person's body' or 'one's soul is taken out of someone's body' instead of 'body being taken out of life'. It would be rather callous to attribute this kind of construal to a single factor, but it is reasonable to speculate that the following factors may have contributed to this interesting reversal: a) the centrality of body in human conceptualization; b) the importance of body as a source of containment; c) cultural significance of, for example, the body being the seat of the soul; d) a lack of linguistic context; e) level of language proficiency. The prominence of the body as a container metaphor is well established, at least in western civilization, and happens to be a quite productive schematic representation - ideas escape our minds, we can get people out of our hearts, viruses enter our bodies, and so on. The reverse construal is thus to be expected. Rather than being naïve, second language learners may be using basic metaphorical construals in acquiring new concepts.

The third group of meanings (G5) had been classified as aspectual (termination). As expected, $11.61 \%$ of the participants' answers suggest that the meaning of the particle denotes some sort of termination. However, a very large number of answers relate to less grammaticalized meanings of out, which again is likely to indicate that linguistic categories may be entered at various points in the process of language acquisition and development. Thus, the second most frequent construal (8.10\%) implies that the particle stands for static displacement. Then, 6.51\% of the answers point to the static topology focused on the space where the conceptualizer is situated, $3.97 \%$ of the answers say that the particle denotes concrete processual topology (together with 2.06\% of the cases with no container specified), and $3.94 \%$ of the answers indicate that out stands for some sort 
of inaccessibility and absence (PC4). If we reorder these answers into a sort of gradient line denoting the process of grammaticalization, we might obtain the order as shown in Figure 11.

\begin{tabular}{|c|c|c|}
\hline $\begin{array}{l}\text { out is 'leaving an } \\
\text { enclosed space' }\end{array}$ & $\begin{array}{l}\text { out is 'leaving and } \\
\text { disappearing' }\end{array}$ & $\begin{array}{l}\text { out is 'out of where we are, } \\
\text { out of our reach' }\end{array}$ \\
\hline
\end{tabular}

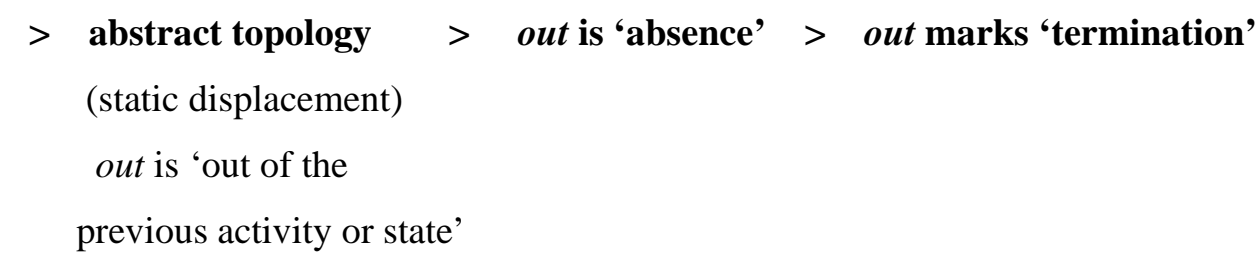

Figure 11. A potential path of grammaticalization in the strategic construal of out (1).

Finally, it is interesting to note the difference in frequencies between the two construals implying static topology (PC3 and PC9). Whereas the frequency of PC3 (concrete static topology with the focus on the conceptualizer's space) is $6.51 \%$, the frequency of PC9 (concrete and abstract topology with the focus outside the conceptualizer's space) is only $1.14 \%$. This may indicate that in terms of the stages in the process of developing or acquiring a network of meanings, the construal of out involving the conceptualizer's space and the construal of out involving the space outside the conceptualizer's dominion are not equally distant from the aspectual meaning of out. In other words, the construal of out involving the conceptualizer's space is closer to the aspectual meaning of out than the construal involving the space outside the conceptualizer's dominion. This again shows the pervasiveness of the concrete and deictic representation of out operating as the base for alternative readings.

The last group of meanings of PVs (G6) is also aspectual, but the meanings seem to be inceptive. Contrary to the results for out denoting termination, the most frequent answers for this group of meanings are not those that refer explicitly to the aspectual 
nature of the particle. The most frequent answers are those labelled PC9 (11.96\%), which imply static topology with the focus on an outer space. We hypothesize that for L2 users of English, the beginning of an activity is identified with the space entering their immediate dominion. Things do not seem to be leaving the space of the conceptualizer, but they become accessible from a hidden region. Things start as they become visible. The accessibility construal is generally quite pervasive. The sun and the moon come out, as well as actors on stage, water from fountains, and so on. It is reasonable to assume that L2 users exploit that kind of construal from their basic experience. Concrete processual topology and explicit reference to aspect are the second most frequent kinds of construal (7.61\%). In the case of processual topology, the users seem to construe the inceptive nature of PVs by assigning it to the particle denoting the process of a TR leaving an enclosed space (and the space is often described as something that confines the TR). Finally, $3.26 \%$ of the answers refer to abstract topology (PC2). In sum, in a similar manner to out signalling termination, strategic construal of out that marks inception shows stages that resemble the process of grammaticalization that is implied in L1 descriptions of this particle (see Figure 12).

$\begin{array}{lll}\begin{array}{l}\text { processual topology } \\ \text { out is 'leaving an } \\ \text { enclosed space' }\end{array} & \begin{array}{l}\text { static topology } \\ \text { (concrete and abstract) } \\ \text { focus on the space outside } \\ \text { the conceptualizer's } \\ \text { dominion }\end{array} & \begin{array}{l}\text { abstract topology } \\ \text { (static topology) } \\ \text { out is 'out of the } \\ \text { previous activity or state' }\end{array}\end{array}$

\section{out marks 'inception'}

Figure 12. A potential path of grammaticalization in the strategic construal of out (2).

\section{III.2.4. Results for in}

1) For the group of meanings classified as G2 (processual topology - concrete), the meaning of in was construed as follows: 
a) PC1 (15.37\%) - processual topology (concrete/physical). In is: entering a new space; getting (in)to a new space (there is some kind of movement involved); getting into a container and the container is specified; going into a certain space; going into a designated area; into a certain piece of space; into a place (see Figure 13).

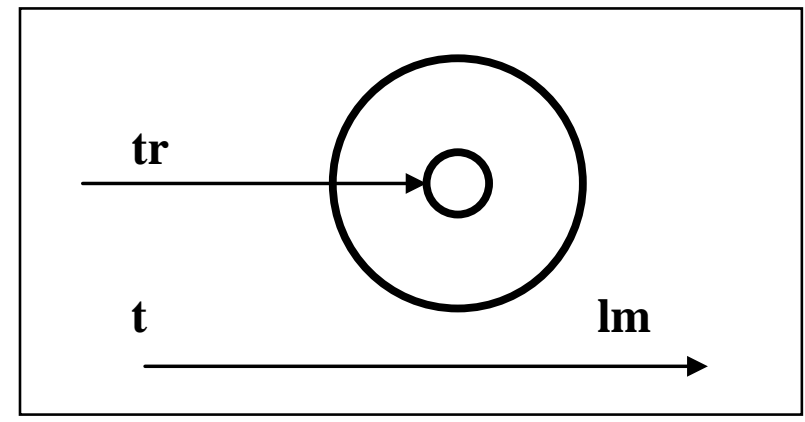

Figure 13. Strategic construal of in - processual topology.

b) PC3 (12.80\%) - static topology (concrete/physical) - there is no motion, just physical space and location. In is: a place; a location; space; limited space; confined space; something like a hiding place (see Figure 14).

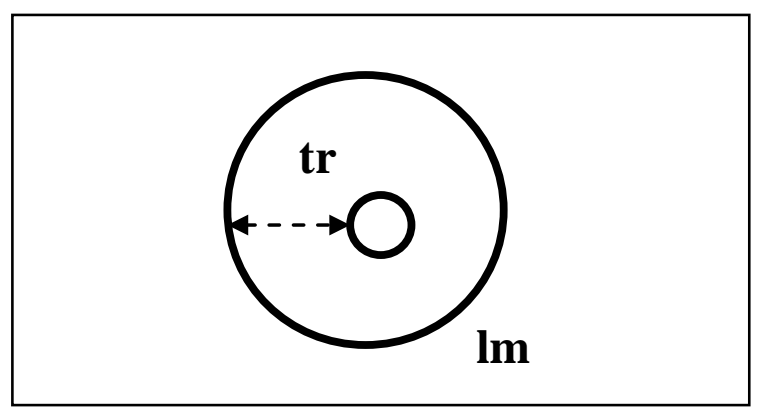

Figure 14. Strategic construal of in - static topology.

c) PC2 (2.48\%) - abstract topology leaning towards the inceptive aspect. In is: be/get (in)to a new activity; be/get (in)to a new situation; (in)to a (new/another) group of people; entering a new situation; beginning of something; starting to get involved. See Figure 15, which represents the inceptive nature of the process constituting this construal $^{18}$. 


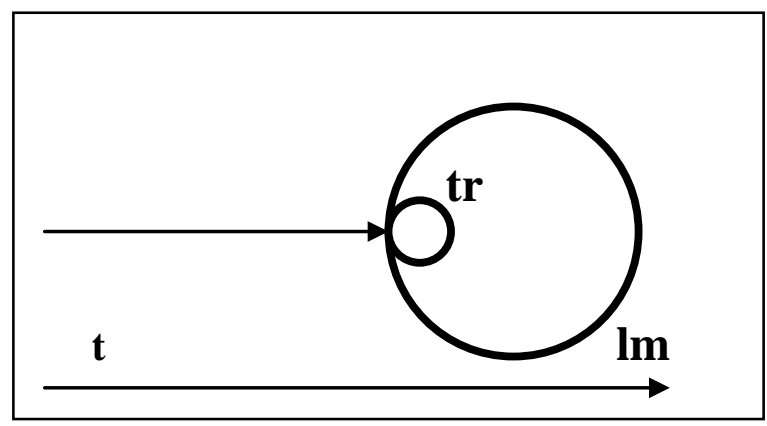

Figure 15. Strategic construal of in - inceptive process.

d) PC4 (3.47\%) - static topology - focus on the subject's dominion. In is: where the subject is, i.e. his/her world; control; dominion; power.

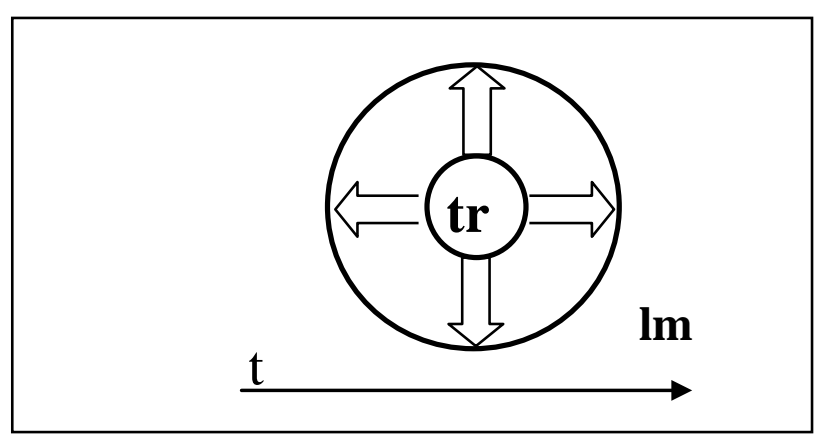

Figure 16. Strategic construal of in - control within dominion.

e) PC5 (2.01\%) - process (concrete and physical, but no container specified). In is: going into; jumping into; moving towards inside; moving inwards; entering; returning (see Figure 17).

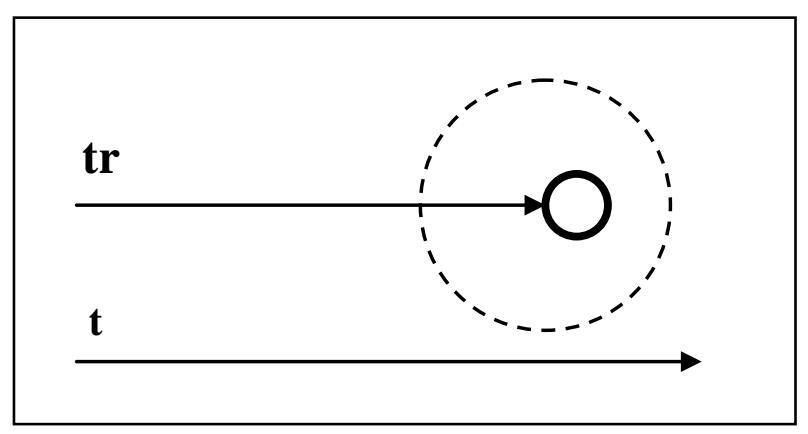

Figure 17. Strategic construal of in - entrance - no container specified.

f) PC6 (2.01\%) - in is: inside, inside of something (not very informative).

g) PC8 (0.11\%) - in intensifies the action.

h) PC11 (2.48\%) - reverse topology. 
i) PC12 (0.11\%) - established metaphor. In is: acceptable and accepting.

2) For G4 - processual topology (abstract), the meaning of in was construed in the following ways:

a) PC1 (17.85\%) - processual topology (concrete/physical). See Figure 13.

b) PC2 (16.91\%) - abstract topology leaning towards the inceptive aspect. See Figure 15.

c) PC3 (3.55\%) - static topology (concrete/physical). See Figure 14.

d) PC4 (2.75\%) - static topology - focus on the subject's dominion.

e) PC5 (1.2\%) - process (concrete and physical, but no container specified). See Figure 16.

f) PC6 (2.29\%) - in is: inside, inside of something (not very informative).

g) PC8 (0.34\%) - in intensifies the action.

h) PC11 (3.08\%) - reverse topology.

i) PC12 (0.17\%) - established metaphor. In is: acceptable and accepting.

Table 2. Strategic construal of in - summary.

\begin{tabular}{|c|c|c|}
\hline $\begin{array}{c}\text { PC1 - processual } \\
\text { topology } \\
\text { (concrete/physical) }\end{array}$ & $\begin{array}{c}\text { G2 (processual topology - } \\
\text { concrete) }\end{array}$ & $\begin{array}{c}\text { For G4 (processual } \\
\text { topology - abstract) }\end{array}$ \\
\hline $\begin{array}{c}\text { PC2 - abstract topology } \\
\text { leaning towards the } \\
\text { inceptive aspect }\end{array}$ & $15.37 \%$ & $17.85 \%$ \\
\hline $\begin{array}{c}\text { PC3 - static topology } \\
\text { (concrete/physical) }\end{array}$ & $2.48 \%$ & $16.91 \%$ \\
\hline $\begin{array}{c}\text { PC4 - static topology - } \\
\text { focus on the subject's } \\
\text { dominion }\end{array}$ & $3.47 \%$ & $2.55 \%$ \\
\hline $\begin{array}{c}\text { PC5 - process (concrete } \\
\text { and physical, but no } \\
\text { container specified) }\end{array}$ & $2.01 \%$ & $2.75 \%$ \\
\hline $\begin{array}{c}\text { PC6 - in is: inside, inside } \\
\text { of something (not very } \\
\text { informative) }\end{array}$ & $2.01 \%$ & $1.20 \%$ \\
\hline
\end{tabular}




\begin{tabular}{|c|c|c|}
\hline $\begin{array}{c}\text { PC8 - in intensifies the } \\
\text { action }\end{array}$ & $0.11 \%$ & $0.34 \%$ \\
\hline PC 11 - reverse topology & $2.48 \%$ & $3.08 \%$ \\
\hline $\begin{array}{c}\text { PC12 - established } \\
\text { metaphor 'acceptable' }\end{array}$ & $0.11 \%$ & $0.17 \%$ \\
\hline
\end{tabular}

\section{III.2.5. Discussion for in}

The first and the most obvious observation is that in is less informative than out, which is relevant to various aspects of the results in both parts of the research (see Geld, this volume). Secondly, there are fewer types of the construal with in than with out, and the learners' answers are shorter and/or less specified in the case of in. Finally, with both groups of meanings (G2 and G4) there are a certain number of answers that explicitly say that in is 'not very informative' (PC6). This is probably due to the much-discussed pervasiveness of the experience of boundedness and containment (Dewell 2005, Johnson 1987, Lakoff 1987), which results in containment being perceived as some kind of 'regular', 'natural' or 'neutral' state of being that is taken for granted. Moreover the marked character of in corresponds to other conceptual phenomena well attested in language. We naturally see and conceptualize what is in front of us, what is on stage (Langacker 2000). Looking at the space we actually occupy implies special effort. This correlates with abundant asymmetry facts in language such as the unmarked status of $3^{\text {rd }}$ person over 1st in pronominal marking, the marked character of reflexive, as opposed to transitive constructions, and the special treatment of inalienable possession. To the extent that in normally designates the location where the conceptualizer is located, the marked character of in is to be expected.

Let us now take a look at the two groups separately. For the group of meanings classified as G2 (processual topology - concrete), the most frequent construal was PC1 (concrete processual topology with reference to the container). Together with PC5 (concrete processual topology with no reference to the container), 17.38\% of the participants identified the meaning of the particle with the meaning we had assigned to the whole PV. The second most frequent construal, PC3 (static topology - 12.80\%), suggests that the participants attended only to the resulting state of the whole image, and they formed a completely stationary image, independent from a preceding path. Considering the fact that our participants were all adults, in whose L1 semantic system 
static locations are considered to be more basic than motion events, it is not surprising that so many of them ignored the dynamic aspect of the underlying schema while constructing this particular meaning in L2.

The last two types of construal that deserve our attention for this group of meanings are PC4 (static topology with the focus on the subject's dominion) and PC11 (reverse or non-egocentric viewing). As stressed by Evans and Tyler in their description of in, there are two clusters of meaning related to the conceptualizer's vantage point: a) the cluster related to the spatial scenes in which the vantage point is located within the location being conceptualized, and b) the cluster related to the spatial scenes in which the vantage point is located outside the spatial region being conceptualized. What the data for G2 show is that, for some users, the most important aspect of meaning construal is the one pertaining to the viewing arrangement in which the vantage point is located within the spatial scene being conceptualized. Thus, $3.47 \%^{\frac{19}{9}}$ of the participants stressed that the most salient aspect of the construal was the focus on the participant's/conceptualizer's dominion. Moreover, a smaller number of them (2.48\%) did the same even when the particle does not actually code this particular viewing arrangement (e.g. in in the PV construction write in meaning 'write to ask or complain' does not code the subject's dominion). If we treat the latter not simply as an error, we may conclude that L2 users recognize certain, more general, facets of the meaning of the particle even when they are not coded in a particular sense that is being processed. This might lead us to believe and conclude that their strategic thinking involves various cognitive processes, such as for example those pertaining to viewing arrangement, which tend to be activated whenever they constitute aspects of construal in L1. In other words, having encountered various facets of meaning and having abstracted a variety of regularities in the process of their L2 learning and processing, users are likely to employ them and construct meaning strategically whenever they face something they do not know or understand completely. Consequently, their strategic thinking does involve errors in a narrow sense of the meaning, but, in broader terms, they should be treated as a meaningful and constructive stage in their progress.

Finally, for the group of meanings G4 (processual topology - abstract), the situation is somewhat different. Even though there is a high percentage of answers implying concrete processual topology (PC1 - 17.85\%), there is also a high percentage of 
answers (16.91\%) pointing to the inceptive aspect of the construal (PC2). The recognition of the abstract nature of the particle in this particular group of meanings is not that surprising. What is more surprising is the users' tendency to go a step further and describe the role of the particle in terms of its aspectual nature. The inceptive aspect of the particle is defined either overtly by using descriptions such as 'beginning of something' or 'starting to get involved', or in a more covert manner by describing its meaning as, for example, 'getting (in)to a new activity' or 'entering a new situation'. Thus, we must conclude that our L2 users of English recognized the aspectual nature of the particle where we, i.e. linguists and researchers, had neither expected nor done so ourselves. A closer look at the two sources for inceptive meanings suggests that this construal is the mirror image of the inceptive meaning provided for out. In the case of out events are initiated as they become accessible from a hidden location. In the case of in accessibility is the default, no hidden location is required. As soon as mental contact is established the event gets started. The high frequency for inceptive in is thus to be expected.

\section{CONCLUSIONS}

Users of English as L2 find both lexicon and grammar meaningful, and they are aware of the symbolic nature of language. The cognitive linguistic premise that language is intimately related to other cognitive processes finds its evidence in the nature of learning strategies employed by L2 users. More specifically, meaning construal in L2 is comparable to meaning construal in L1. This is especially apparent in users' construal of particles. They recognize the complexity of their semantic networks proposed and described in English as L1. Their answers clearly imply the problem of dynamic aspects of the construal of particles as well as the importance of cognitive processes such as attention and perspective (e.g. their answers imply gradience from the literal to the metaphorical, aspects of viewing arrangement, and mental scanning). In other words, their cognitive strategies employed in the process of meaning construction in L2 reflect general cognitive processes described as aspects of construal in L1. Even though the realizations of these processes are language-specific and languages have different inventories for building their conceptual structures, the fact that cognitive processes are 
intimately related to language enables L2 users to activate them in the process of meaning construal. What the data show is that their ability to go from the literal and concrete to the abstract and metaphorical results in a variety of strategically constructed meanings amounting to a gradient scale resembling a grammaticalization path of English particles. For example, their answers for out in the group of PV meanings implying aspect (termination) indicate that they make sense of meanings in a linguistically motivated way, that they are tacitly aware of the fact that lexicon and grammar form a continuum, and that their meaning construal involves general cognitive processes such as attention, comparison and perspective, i.e. linguistic construal operations such as selection, scalar adjustment, metaphor, vantage point, and so forth, as instances of these general processes. This is made clear in the following grammaticalization path: out is 'leaving an enclosed space' (processual topology) > out is 'leaving and disappearing' (processual topology, no container specified) > out is 'out of where we are, out of our reach' (static topology - concrete) > out is 'out of the previous activity or state (abstract topology - static displacement) > out is 'absence' > out marks 'termination'. The path also shows an obvious subjectification path where the core meaning undergoes attenuation (Langacker 2000b). Some properties of the basic meaning of out lose prominence in favour of a less central feature to actually construe more schematic representations. First the notion of boundary is lost, and then the presence of the source locations is blurred. Moreover, the space is no longer a concrete one and finally abandonment of a previous stage triggers the aspectual notion of termination. We may claim that the basic notion of containing space remains at the base to support the emergence of abstract meanings.

Another example of our users' varying attention relates to the mental scanning underlying dynamic and static aspects of their meaning construal. For example, even though conceptual scanning processes are an essential element for both path schemas and stative relations, our learners' attention was often rather selective and they attended only to the resulting states and described completely stationary images rather than processes.

Finally, aspects of viewing arrangement pertaining to the general cognitive process of perspective are more than evident in the types of strategic construal implying the 
importance of the conceptualizer's dominion or the space outside of her/his dominion (see construals PC3 and PC9 for out, and PC4 for in).

The way our participants constructed particular meanings supports the idea that speakers of English have different starting points within a lexical category. It is true that the topological representation is dominant, but alternative ways of construing meaning are at hand. Where and how they start is likely to depend on various factors pertaining to their experience and knowledge (e.g. the work they do, hobbies they have, places they live in), and to individual strategies employed to conform to events. For example, there are users who construct concrete meanings in a more abstract way. The meaning of out in the verb put out meaning 'to injure your back, shoulder or hip' is more likely to be construed as concrete and topological by someone who knows exactly what happens when such an injury occurs - a particular bone gets 'out of its place'. On the other hand, it can be easily identified with a more abstract meaning such as 'out of the original or normal state' by those who have never seen or experienced such an injury or have never thought about it. However, predicting our learners' starting points within a lexical category, if possible at all, would require the introduction of a number of relevant variables and a thorough investigation of various aspects of language learning. However, we can still conclude that our participants' meaning construction supports the idea that the best way to deal with complex lexical categories is to avoid strict categorization which assumes fixed and predictable places of particular meanings within a particular category. Our participants' construals exhibit partial compositionality which is evident in their selection of one or two outstanding properties from the whole set of possible features of each PV. Furthermore, they seem to extract regularities from particular constructions and construct meaning accordingly, but they are free to pull out multiple patterns from a given set of forms. Crucially, these patterns do not vary in all possible directions. They exploit the possibilities of the base form in patterns of attenuation and subjectification that profile different facets of the base form as pertaining to the dominion they apply. The flexibility to construe in or out, in a concrete or an abstract manner, simply obeys the most fundamental topological schematic representation of these forms in such a way that the freedom in the conceptualizer's vantage point is framed by the basic cognitive patterns we have sketched in this paper. 
Given these cognitive patterns, the abundant similarities in event construal between second- and first-language users’ strategic construal should be anything but surprising.

\section{Notes}

${ }^{1}$ See also Geld this volume as a complement to this article.

${ }^{2}$ Discussions on degrees of idiomaticity of English particle verbs as composite wholes are numerous (see for example Bolinger 1971, Celce-Murcia and Larsen-Freeman 1999, Cornell 1985, Dagut and Laufer 1985, Dirven 2001, Gries 2003, Laufer and Eliasson 1993, Liao and Fukuya 2004, Lindner 1981, Makkai 1972, McPortland 1989, O’ Dowd 1998, Quirk et al. 1985). Even the content of phrasal-verb dictionaries varies according to the type of meanings included: for example, Sinclair and Moon (1989) and Cullen and Sargeant (1996) include both literal and idiomatic phrasal verbs, whereas Cowie and Mackin (1993) exclude the former. See also Cappelle (2005: 120) for a two-way grid classifying particle verbs in terms of literal and idiomatic meanings assigned to their component parts.

Relevant parallelism related to gradient idiomaticity is also found in the field of idioms. For example, Gibbs claims that chew the fat and kick the bucket are much less analyzable than e.g. pop the question or blow your stack (1995: 100).

${ }^{3}$ The building-block metaphor was used by Langacker $(1987,2000)$ to portray the way linguists tend to think about morphological and syntactic composition.

${ }^{4}$ This view of language acquisition is shared by various constructivists, for example, the connectionists (Christiansen and Chater 2001, Christiansen et al. 1999, Plunkett 1998), functional linguists (Bates and MacWhinney 1981, MacWhinney and Bates 1989), emergentists (Elman et al. 1996), cognitive linguists (Croft and Cruse 2004, Lakoff 1987, Langacker 1987, 1991), constructivist child-language researchers (Slobin 1997, Tomasello 1992, 1995, 2000) and many others.

$\underline{5}$ These constraints are especially evident in adult L2 learning (see for example Doughty 2003).

${ }^{6}$ See the introduction of Geld (this volume) to have the typology explained.

${ }^{7}$ For issues related to negotiation of form prompted by negotiation of meaning see e.g. Brock et al. (1986), Day et al. (1983), Foster and Ohta (2005), Skehan and Foster (2001).

${ }^{\stackrel{8}{9}}$ See also the results in Section IV of Geld's article (this volume).

- See Geld's abstract (this volume).

${ }^{10}$ See Section III.1, The instrument, in Geld's article (this volume).

${ }^{11}$ The main stage was preceded by a pilot study to test the reliability of the questionnaire.

12 The third category was lexical determination. The three categories (topological, lexical and compositional) were the results of the first part of the research (see Geld this volume).

$\underline{13}$ The following learners' dictionaries were consulted while designing the questionnaire used in this research: Oxford Phrasal Verbs: Dictionary for Learners of English (Parkinson 2001) and Cambridge Phrasal Verbs Dictionary (Walter 2006).

${ }^{14}$ See Section III-3 in Geld's article (this volume) for complementary data.

$\underline{15}$ It should be stressed that this percentage (3.25\%) is viewed in relation to the frequency of other contributions. In other words, if we know that there were 10 types of construal identified for out, and that the highest percentage for this group of meanings was $12.10 \%$, followed by $11.50 \%$ and $7.55 \%$, and that most other frequencies were below $2.0 \%$, it seemed reasonable to consider PC2 (3.25\%) in our discussion and attempt to interpret its contribution.

${ }^{16}$ Rice analysed longitudinal data obtained from the CHILDES corpus for two English-speaking children and the results showed that there are significant differences in usage patterns for the prepositions she studied, and that each child has a "different point of entry" into one of the nine lexical categories (2003: 272). Rice concludes that the findings suggest that semantic extension within a lexical category proceeds outwardly only partially from some basic, concrete sense, and that the child language evidence presented in the analysis is "inconclusive about any parallelisms which might obtain between developmental and diachronic extension” (ibid.: 273).

${ }^{17}$ Here, Lindner uses the term category in a narrower sense of its meaning. It actually refers to a cluster of meanings that make similar semantic contributions in particular groups of PV constructions. 
$\underline{18}$ This particular construal combines two important aspects of the construal of in in L2. First, it implies abstract topology and, second, it points to a more grammaticalized meaning that codes the inceptive aspect that has not been discussed for in in L1.

$\underline{19}$ We believe that a qualitative analysis such as ours needs to include and interpret even seemingly less significant contributions, especially in the light of our insistence on illuminating subjective and idiosyncratic aspects of (strategic) construal.

\section{REFERENCES}

Bates, E. and MacWhinney, B. 1981. "Second language acquisition from a functionalist perspective”. In Winitz, H. (Ed.) Native Language and Foreign Language Acquisition, Annals of the New York Academy of Science, vol. 379. New York, NY: The New York Academy of Sciences, 190-214.

Bennett, D.C. 1975. Spatial and Temporal Uses of English Prepositions: An Essay in Stratificational Semantics. London: Longman.

Bolinger, D. 1971. The Phrasal Verb in English. Cambridge, Mass.: Harvard University Press.

Bowerman, M. 1996a. “The origins of children's spatial semantic categories: Cognitive versus linguistic determinants”. In Gumperz, J.J. and S. C. Levinson (Eds.) Rethinking Linguistic Relativity. Cambridge: Cambridge University Press, 145176.

Bowerman, M. 1996b. "Learning how to structure space for language”. In Bloom, P., M. A. Peterson, L. Nadel and M.F. Garrett (Eds.) Language and Space. Cambridge, MA: MIT Press, 383-435.

Bowerman, M. and Choi, S. 2003. "Space under construction: Language-specific categorization in first language acquisition”. In Genter D. and S. Goldin-Meadow (Eds.) Language in Mind: Advances in the Study of Language and Thought. Cambridge, MA: MIT Press, 387-427.

Brock, C., Crookes, G., Day, R. and Long M. 1986. “The differential effects of corrective feedback in native speaker / non-native speaker conversation”. In Day, R. (Ed.) Talking to Learn: Conversation in Second Language Acquisition. Rowley, MA: Newbury House, 327-351. 
Brugman, C. 1981. Story of Over. M.A. thesis, University of California, Berkeley. Indiana University Linguistics Club.

Cappelle, B. 2005. Particle Patterns in English. Ph. D. dissertation. Leuven: Katholieke Universiteit Leuven.

Casad, H.E. and Langacker, R.W. 1985. “'Inside’ and ‘outside’ in Cora grammar”. International Journal of American Linguistics, 51, 247-281.

Celce-Murcia, M. \& Larsen-Freeman, D. 1999. The Grammar Book. An ESL/EFL Teacher's course. Boston: Heinle and Heinle.

Christiansen, M.H. and Chater, N. 2001. "Connectionist Psycholinguistics: Capturing the empirical data”. Trends in Cognitive Sciences, 5, 82-88.

Christiansen, M.H., Chater, N. and Seidenberg, M.S. 1999. "Connectionist model of human language processing: progress and prospects”. Cognitive Science (Special issue), 23, 415-634.

Choi, S. and Bowerman, M. 1991. "Learning to express motion events in English and Korean: The influence of language-specific lexicalization patterns”. Cognition, 41, 83-121.

Cornell, A. 1985. "Realistic goals in teaching and learning phrasal verbs”. IRAL, 23, 269-280.

Cowie, A.P. and Mackin, R. 1993. Oxford Dictionary of Phrasal Verbs. Oxford: Oxford University Press.

Croft, W. and Cruse, D.A. 2004. Cognitive Linguistics. Cambridge: Cambridge Univesity Press.

Cullen, K. and Sargeant, H. 1996. Chambers Dictionary of Phrasal Verbs. Edinburgh: Chambers Harrap.

Dagut, M. and Laufer, B. 1985. "Avoidance of phrasal verbs - a case for contrastive analysis”. Studies in Second Language Acquisition, 7, 73-80.

Day, R., Chenoweth, N., Chun, A. and Luppescu, S. 1983. "Foreign language learning and the treatment of spoken errors”. Language Learning and Communication, 2, 215-224. 
Dewell, R. 2005. "Dynamic patterns of CONTAInMENT”. In Hampe, B. (Ed.) From Perception to Meaning, Image Schemas in Cognitive Linguistics. Berlin/ New York: Mouton de Gruyter, 369-393.

Dirven, R.W. 2001. “English phrasal verbs: Theory and didactic application”. In Pütz M., S. Niemeier and R. Dirven (Eds.) Applied Cognitive Linguistics I: Theory and Language Acquisition. Berlin/New York: Mouton de Gruyter, 3-27.

Doughty, C.J. 2001. “Cognitive underpinnings of focus on form”. In Robinson, P. (Ed.) Cognition and Second Language Instruction. Cambridge: Cambridge University Press, 206-257.

Doughty, C.J. 2003. “Instructed SLA: Constraints, compensation, and enhancement”. In Doughty, C.J. and M.H. Long (Eds.) Handbook of Second Language Acquisition. Oxford: Blackwell, 256-310.

Ellis, N.C. 2003. "Constructions, chunking, and connectionism: The emergence of second language structure”. In Doughty, C. and M. Long (Eds.) The Handbook of Second Language Acquisition. Malden/Oxford/Melbourne/Berlin: Blackwell Publishing, 63-103.

Elman, J.L., Bates, E.A., Johnson, M.H., Karmiloff-Smith, A., Parisi, D. and Plunkett, K. 1996. Rethinking Innateness: A Connectionist Perspective on Development. Cambridge, MA: MIT Press.

Evans, V. and Tyler, A. 2004. "Spatial experience, lexical structure and motivation: The case of in”. In Radden, G. and K.-U. Panthe, (Eds). Studies in Linguistic Motivation. Berlin/New York: Mouton de Gruyter, 157-192.

Fillmore, C.J. 1968. “The case for case”. In Bach, E. and R.T. Harms (Eds.) Universals in Linguistic Theory. New York: Academic Press, 27-63.

Foster, P. and Ohta, A. 2005. "Negotiation for meaning and peer assistance in second language classroom”. Applied Linguistics, 26, 402-430.

Geld, R. 2006. “Strateško konstruiranje značenja engleskih fraznih glagola” [Strategic constral of English phrasal verbs]. Jezikoslovlje, 7 (1-2), 67-111. 
Geld, R. and Letica Krevelj, S. 2011. "Centrality of space in the strategic construal of up in English particle verbs”. In Brdar, M., M. Omazić, G. Buljan, V. Bagarić and T. Gradečak-Erdeljić (Eds.) Space and Time in Language. Frankfurt/New York: Peter Lang Verlag, 145-166.

Gibbs, R.W. 1995. “Idiomaticity and Human Cognition”. In Everaert, M., E. Van der Linden, A. Schenk and R. Schreuder (Eds.) Idioms: Structural and Psychological Perspectives. Hillsdale New Jersey: Lawrence Erlbaum Associates, 97-116.

Gries, S.T. 2003. Multifactorial Analysis in Corpus Linguistics: A Study of Particle Placement. London: Continuum.

Herskovits, A. 1982. Space and Prepositions in English: Regularities and Irregularities in a Complex Domain. Ph. D. Dissertation. Stanford, CA: Stanford University.

Herskovits, A. 1988. "Spatial expressions and the plasticity of meaning”. In RudzkaOstyn, B. (Ed.) Topics in Cognitive Linguistics. Amsterdam/Philadelphia: John Benjamins, 271-287.

Hulstijn, J.H. 1989. "Implicit and incidental second language learning: experiments in the processing of natural and partly artificial input”. In Dechert, $\mathrm{H}$. and $\mathrm{M}$. Raupach (Eds.) Interlingual Processes. Tübingen Gunter Narr, 49-73.

Jackendoff, R. 1983. Semantics and Cognition. Cambridge, Mass.: MIT Press.

Johnson, M. 1987. The Body in the Mind. The Bodily Basis of Meaning, Imagination, and Reason. Chicago/London: The University of Chicago Press.

Lakoff, G. 1987. Women, Fire and Dangerous Things: What Categories Reveal About the Mind. Chicago/London: The University of Chicago Press.

Langacker, R.W. 1982. “Space grammar, analyzability, and the English passive”. Language, 58, 22-80.

Langacker, R.W. 1987. Foundations of Cognitive Grammar, vol. 1, Theoretical Prerequisites. Stanford: Stanford University Press.

Langacker, R.W. 1991. Foundations of Cognitive Grammar, vol. 2, Descriptive Application. Stanford: Stanford University Press. 
Langacker, R.W. 2000a. Grammar and Conceptualization. Berlin/New York: Mouton de Gruyter.

Langacker, R.W. 2000b. "Subjectification and gramaticization" Grammar and Conceptualization. Berlin/New York: Mouton de Gruyter, 297-316.

Laufer, B. and Eliasson, S. 1993. "What causes avoidance in L2 learning? L1-L2 difference, L1-L2 similarity, or L2 complexity?”. Studies in Second Language Acquisition, 15, 35-48.

Liao, Y. and Fukuya, Y.J. 2004. “Avoidance of phrasal verbs: The case of Chinese learners of English”. Language Learning, 54 (2), 193-226.

Lindner, S.J. 1981. A Lexico-Semantic Analysis of English Verb Particle Constructions with OUT and UP. Ph. D. dissertation. San Diego, CA: University of California.

MacWhinney, B. 2001. “The competition model: The input, the context, and the brain”. In Robinson, P. (Ed.) Cognition and Second Language Instruction. Cambridge: Cambridge University Press, 69-90.

MacWhinney, B. 2006. "Emergent fossilization". In Han, Z-H. and T. Odlin (Eds.) Studies of Fossilization in Second Language Acquisition. Clevedon: Multilingual Matters.

MacWhinney, B. and Bates, E. (Eds.) (1989). The Crosslinguistic Study of Sentence Processing. New York: Cambridge University Press.

Makkai, A. 1972. Idiom Structure in English. The Hague: Mouton.

McPortland, P. 1989. "The acquisition of phrasal verbs by non-native speakers of English”. CUNYorum, 14, 150-156.

O’Dowd, E.M. 1998. Prepositions and Particles in English. A Discourse-functional Account. New York/Oxford: Oxford University Press.

O’Malley, J.M. and Chamot, A.-U. 1990. Learning Strategies in Second Language Acquisition. Cambridge: Cambridge University Press.

Parkinson, D. (Ed.) 2001. Oxford Phrasal Verbs: Dictionary for Learners of English. Oxford: OUP. 
Plunkett, K. (Ed.) 1998. Language and Cognitive Processes, 13. Special issue on connectionist models of language.

Quirk, R., Greenbaum, S., Leech, G. and Svartvik, J. 1985. A Comprehensive Grammar of the English Language. London: Longman.

Rice, S. 2003. “Growth of a lexical network: Nine English prepositions in acquisition”. In Cuyckens, H., R. Dirven and J.R. Taylor (Eds.) Cognitive Approaches to Lexical Semantics. Berlin/New York: Mouton de Gruyter, 243-260.

Rudzka-Ostyn, B. 2003. Word Power: Phrasal Verbs and Compounds, A Cognitive Approach. Berlin/New York: Mouton de Gruyter.

Schmidt, R. 1990. "The role of consciousness in second language learning”. Applied Linguistics, 11, 129-58.

Schmidt, R. 1993a. "Consciousness, learning and interlanguage pragmatics". In Kasper, G. and S. Blum-Kulka (Eds.). Interlanguage Pragmatics. New York: Oxford University Press, 21-42.

Schmidt, R. 1993b. “Consciousness in second language learning: introduction”. Paper presented at AILA $10^{\text {th }}$ World Congress of Applied Linguistics, Amsterdam.

Schmidt, R. 1994a. "Deconstructing consciousness in search of useful definitions for applied linguistics”. AILA Review, 11, 11-26.

Schmidt, R. 1994b. "Implicit learning and the cognitive unconscious: of artificial grammars and SLA". In Ellis. N. (Ed.) Implicit and Explicit Learning of Languages. London: Academic Press, 165-209.

Schmidt, R. 1998. “Attention”. University of Hawai'i Working Press in ESL, 15, 1-34.

Schmidt, R. 2001. “Attention”. In Robinson, P. (Ed.) Cognition and Second Language Instruction. Cambridge: Cambridge University Press, 1-32.

Sinclair, J. and Moon, R. 1989. Collins COBUILD dictionary of phrasal verbs. London and Glasgow: Collins.

Skehan, P. and Foster, P. 2001. “Cognition and tasks”. In Robinson, P. (Ed.). Cognition and Second Language Instruction. Cambridge: Cambridge University Press, 183-205. 
Slobin, D.I. 1997. "The origin of grammaticizable notions: Beyond the individual mind”. In Slobin, D.I. (Ed.). The Crosslinguistic Study of Language Acquisition, vol. 5. Mahwah, NJ: Lawrence Erlbaum, 265-323.

Talmy, L. 1982. "Borrowing semantic space: Yiddish verb prefixes between Germanic and Slavic”. Proceedings of the Eight Annual Meeting of the Berkeley Linguistics Society. Berkeley, Calif.: Berkeley Linguistics Society.

Talmy, L. 1983. "How language structures space”. In Pick, H.L. Jr. and L.P. Acredolo (Eds.) Spatial Orientation: Theory, Research, and Application. New York: Plenum Press, 225-282.

Talmy, L. 2000a. Toward a Cognitive Semantics, vol. 1: Concept Structuring Systems. Cambridge, Mass.: MIT Press.

Talmy, L. 2000b. Toward a Cognitive Semantics, vol. 2: Typology and Process in Concept Structuring. Cambridge, Mass.: MIT Press

Tenbrink, T. 2007. Space, Time, and the Use of Language. Berlin/New York: Mouton de Gruyter.

Tomasello, M. 1992. First Verbs: A Case Study of Early Grammatical Development. Cambridge: Cambridge University Press.

Tomasello, M. 1995. "Language is not an instinct”. Cognitive Development, 10, 131156.

Tomasello, M. 2000. “Do young children have adult syntactic competence?”. Cognition, 74, 209-253.

Vandeloise, C. 1984. Description of Space in French. Ph. D. dissertation. San Diego, CA: University of California.

Vandeloise, C. 1991. Spatial Prepositions: A Case Study in French. Chicago: The University of Chicago Press.

Vandeloise, C. 1994. "Methodology and analyses of the preposition in". Cognitive Linguistics, 5, 157-185.

Walter, E. (Senior Ed.) 2006. $2^{\text {nd }}$ rev. ed. Cambridge Phrasal Verbs Dictionary. (First ed. 1997). Cambridge: Cambridge University Press. 
Zubin, D. and Svorou, S. 1984. “Orientation and gestalt: Conceptual organizing principles in the lexicalization of space”. In Testen, V.M. and J. Drogo (Eds.) Procedings of the $20^{\text {th }}$ Meeting of the Chicago Linguistic Society, Parasession on Lexical Semantics. Chicago: Chicago Linguistic Society, 333-345.

Received November 2011

Cite this article as:

Geld, R. and Maldonado, R. 2011. "Strategic construal of in and out in English particle verbs (PVs)". Language Value, 3 (1), 76-113. Jaume I University ePress: Castelló, Spain. http://www.erevistes.uji.es/languagevalue.

ISSN 1989-7103

Articles are copyrighted by their respective authors 